\title{
Antropofagia marginal periférica ecoando das favelas
}

\section{Marginal peripheral anthropophagy echoing from favelas}

\author{
Raffaela Fernandez
}

Universidade Federal do Rio de Janeiro

Fernanda Mara Campos Leite

Universidade Federal do Rio de Janeiro

DOI: https://doi.org/10.5902/2176148537239

\begin{abstract}
Resumo: O presente texto trata da literatura produzida nas favelas paulistas, especificamente do Sarau da Cooperifa, analisando os percursos desse movimento artístico e cultural atrelados a um aspecto de ordem política e militante como forma de resistir através da literatura. Foi interessante observar como o "Manifesto da antropofagia periférica" se constituiu como uma aporia de combate aos ditames da antropofagia modernista, questionada de igual maneira por escritores que buscam afirmar suas identidades e literaturas que circulam para além de espaços de consagração dos cânones de poder.
\end{abstract}

Palavras-chave: Literatura Marginal periférica. Antropofagia. Literatura Brasileira. Sarau.

Resume: The present text deals with the literature produced in the favelas of São Paulo, specifically the Cooperifa's poetry gathering, analyzing the paths of this artistic and cultural movement linked to an aspect of political and militant order as a way of resisting through literature. It's interesting concerning how the "Manifesto of peripheral anthropophagy" was constituted as an appliance to combat the dictates of Modernist anthropophagy, equally questioned by writers who seek to affirm their identities and literatures that surrounds beyond spaces of consecration of the canons of power.

Keywords: Marginal Literature. Anthropophagy. Brazilian Literature. Poetry slam 
Na obra Cooperifa: antropofagia periférica ${ }^{1}$, o poeta Sérgio Vaz traça panorama histórico do movimento literário denominado por seu idealizador como Sarau da Cooperifa ou "quilombo da poesia", iniciado em 2001 no Jardim Miriam na cidade de São Paulo. Até hoje, todas as quartas-feiras por volta de 200 pessoas se aglomeram no Bar do Zé Batidão para recitarem poemas de autores consagrados e não consagrados dando ênRaffaela fase aos segundos. Esse encontro expressa o desejo de mudança na periFernandez

Fernanda Mara

Campos Leite feria e não de mudar da periferia. Serviu de inspiração para a criação de mais de 40 saraus nas periferias de São Paulo, como por exemplo, Sarau da Brasa e Elo da corrente.

Como nos conta o poeta, a primeira manifestação cultural desse grupo aconteceu em 2001 num galpão (uma fábrica desocupada), onde um candidato a vereador estava estampando camisetas. Em seguida o movimento foi se tornando cada vez mais autônomo, como sugere Sérgio Vaz, e aprimorando o sentido da palavra que nomeia o objetivo do sarau: Cooperifa $=$ cooperação + periferia .

O sarau da Cooperifa vem somar-se às manifestações culturais da periferia que acabaram por definir, organizar, valorizar, metamorfosear e construir uma identidade para o lugar e para o homem periférico. Lugar este construído a partir dos restos trazidos por um centro consumidor e criador de códigos dominantes, mas que, no entanto, foi e é continuamente abalado por essa nova proposta de resgate ao que há de mais genuíno nas margens da cidade através da expressão poética.

Os poetas da Cooperifa têm como objetivo trazer o centro para os becos e vielas das periferias. Não importar a arte, mas produzi-la no seio de sua realidade cultural. Assim, apropriando-se desse espaço de um modo diferenciado, isto é, unindo arte e conhecimento, identidade e reconhecimento de um povo esquecido.

Exemplo disso foi a "Semana de Arte Moderna na Periferia", quando foi divulgado o "Manifesto da Antropofagia Periférica" (VAZ, 2008, p.246-250), assim como o conteúdo do texto, o cartaz traz um desenho que parodia ao quadro de Di Cavalcanti, escolhido para o cartaz dos modernistas nos anos de 1920. Segundo Vaz essa atitude tinha o objetivo de provocar a elite acadêmica.

1 VAZ, Sergio. Cooperifa: antropofagia periférica. Rio de Janeiro: Aeroplano, 2008. 


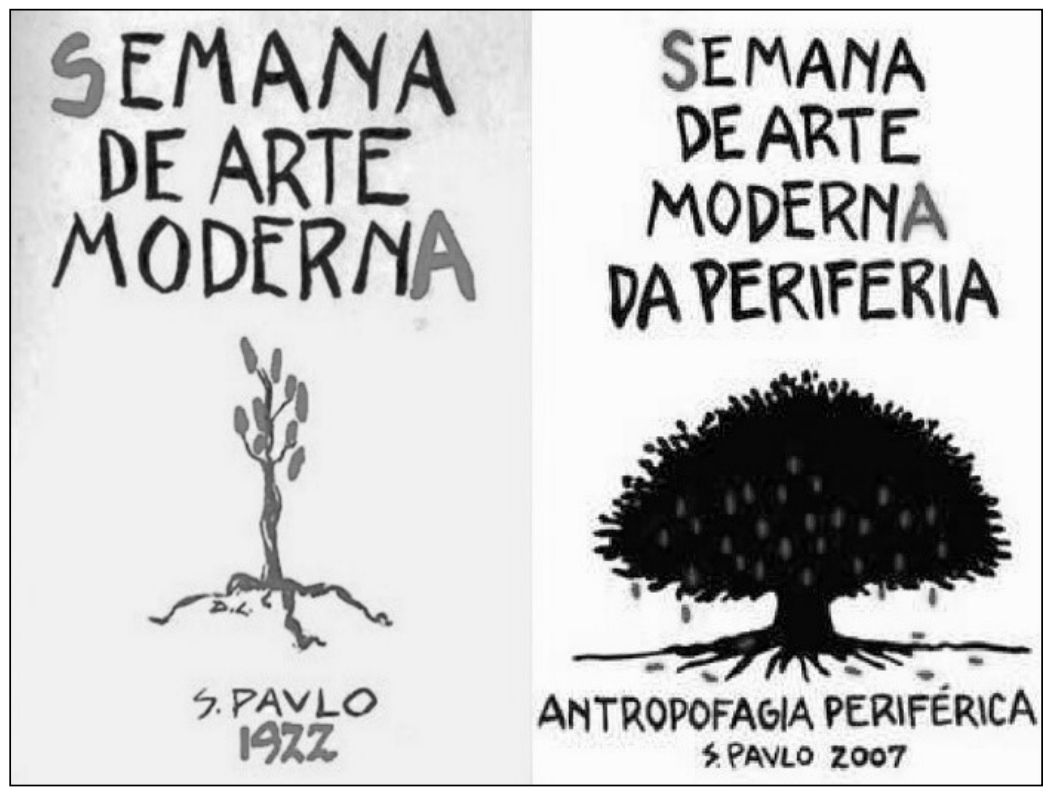

Antropofagia marginal periférica ecoando das favelas

Figura 1 - Comparação entre cartaz da Semana da Arte Moderna e da Semana de Arte Moderna da Periferia.

Disponível em: <http://www.aescotilha.com.br/tag/manifesto-da-antropofagia-periferica/>.

Se nos detivermos à análise da imagem, podemos perceber o contraste de ideias e posicionamentos que compõem a figura a ser usada como convite da Semana de Arte Moderna (1922) e a da Semana de Arte Moderna das Periferias (2007). Primeiro, desenvolvamos um pensamento acerca da ideia de antropofagia em relação às duas imagens: no primeiro cartaz temos como seio da discussão o homem a devorar outro homem do ponto de vista da colonização, esta que nos é de conhecimento histórico; já, na segunda, se coloca para nós uma ideia de canibalismo no interior da metrópole. Aqui, então, falamos de um oprimido e um opressor de origem comum - a cidade como um todo, mas que sofrem as influências da segregação.

Comecemos pela atenta observação às árvores, a primeira diferencia-se da segunda - claramente- pela vitalidade, isto é, apontando-nos que a periferia celebra a vida em todas as instâncias, enquanto a segunda definha em suas próprias escolhas. $O$ sofrimento na periferia não leva para um fim, pelo contrário, é justamente o sofrimento compartilhado e articulado daqueles que a povoam que confere a este espaço um jogo de cintura para se esquivar da seca, leia-se - das migalhas que lhe são reservadas; do frio, leia-se - da frieza com que são endereçados a eles os olhares e julgamentos. 
A concepção etnocêntrica que valoriza a cultura do homem europeu em detrimento de outras culturas, se estende aos grandes centros urbanos fazendo com que os homens a reproduzam sobre as favelas; talvez, porque nas favelas, em sua maior parte vivem pessoas negras, representando assim no imaginário social o lugar da vulnerabilidade, ou ainda, o local da subserviência. Desse modo, ambas as ideias de Raffaela antropofagia surgem sob o apelo, ora ao brasileiro que se alimente do Fernandez

Fernanda Mara

Campos Leite brasileiro, ora do favelado que se alimente do favelado; pois, tanto a sociedade europeia quanto a sociedade urbana brasileira os regurgitam numa espécie de profunda recusa a humanidade que os anima.

$\mathrm{Em}$, Arqueologia da violência ${ }^{2}$, Pierre Clastres nos coloca face a face com o etnocídio global, sendo este a destruição sistemática dos modos de vida e pensamento de povos diferentes daqueles que empreendem essa destruição. No entanto, é possível pensá-lo no interior das cidades na medida em que os centros corroboram com o arrasamento das margens, mais que isso, alienando-as com o discurso salvífico da "guerreiragem individual" ${ }^{3}$ enquanto as agride física e psicologicamente.

Assim, se todo genocídio é o extremo ato de um etnocídio, conseguimos fundamentar a violência que percorre as entranhas das comunidades paulistanas e de todo o Brasil. É, sobretudo, pela ideia que se instalam e sustentam discursos como o de "bandido bom é bandido morto", sem levar em conta o pleno abandono político, econômico e cultural em que se encontram os moradores deste "não-lugar", enquanto lugar negado pela sociedade. Nos cartazes, podemos observar os frutos vermelhos, referindo-se ao sangue que jorrou e jorra da tentativa exorbitante de sublimação ${ }^{4}$ da existência marginal.

Se nos fixarmos um pouco mais na segunda imagem que antropofagia a primeira, vemos que os frutos que caem da copa da árvore permanecem como uma lembrança pertinente a revigorar o ânimo, e remanejar os esforços daqueles que ficaram resistindo às mazelas e um Brasil que guarda uma potência; daí a grandiosa articulação interna das periferias para se manter, socialmente, economicamente e culturalmente firmes mediante os atentados implícitos e explícitos que lhes são violentamente impostos. Esforço, este, a cada dia convertido em força política e empe-

CLASTRES, Pierre. Arqueologia da Violência. São Paulo, Caosac Naify, 2004.

3 Termo empregado por Allan da Rosa no conto "O iludido", a integrar o livro Reza de mãe, para referir-se à ideia de meritocracia.

4 FREUD, Sigmund. Esboço de psicanálise. São Paulo: Imago Editora, 1998. 
nho de valorização de uma identidade mais ampla para o ser periférico, a julgar pelos movimentos dos saraus, que movimentam boa parte da comunidade, desde quem expõe até o dono do bar (muitas das vezes, expoente), no fomento da voz que não se permite mais calar e ser calada.

Além disso, não poderíamos não nos ater à provocação realizada na oposição das imagens, como já dissemos, em especial a crítica ao monopólio do saber, figurado pela academia. Como afirma Sérgio Vaz, "A Arte que liberta não pode vir da mão que escraviza", bem como o conhecimento. Ainda mais se entendermos o conhecimento como resultado de um saber relacional, da maneira como nos sugere Axel Honneth ${ }^{5}$, o que temos é uma imposição dos saberes científicos sobre os saberes populares, ou seja, impossibilitada de reconhecer o valor do outro devido a um pensamento circular que tem início e fim na academia.

Antropofagia marginal periférica ecoando das favelas

Se o (re)conhecimento é da ordem do relacional, somente um relacionamento saudável poderia dar conta da discriminação positiva ${ }^{6} \mathrm{em}$ favor de uma atitude de reparação que tomasse por orientação o tratamento temporário diferenciado de quem está, de fato, em diferença. Mas, como isso não ocorre, são pensados - pela margem- modos de inserção realísticos capazes de envolver as diligências da periferia. Uma inserção, como já salientamos, disposta à mudança na e não mudança da periferia.

O Manifesto Antropófago das Periferias emerge, então, deste despertar artístico em favor da diversidade social, pela democratização e refinamento das políticas públicas (como educação, saúde, esporte, lazer etc.), pelo protagonismo em relação às narrativas que lhes acometem, entre outras tantas:

\section{MANIFESTO DA ANTROPOFAGIA PERIFÉRICA}

A Periferia nos une pelo amor, pela dor e pela cor. dos becos e vielas há de vir a voz que grita contra o silêncio que nos pune. Eis que surge das ladeiras um povo lindo e inteligente galopando contra o passado. A favor de um futuro limpo, para todos os brasileiros. A favor de um subúrbio que clama por arte e cultura, e universidade para a diversidade. Agogôs e tamborins acompanhados de violinos, só depois da aula.

5 HONNETH, Axel. Luta por reconhecimento: a gramática moral dos conflitos sociais. Trad. de Luiz Repa. São Paulo: Ed. 34, 2003.

6 Definição precisa da clientela e das zonas singulares do espaço social e desenvolvimento de estratégias específicas para elas. 


\section{Raffaela \\ Fernandez}

Fernanda Mara

Campos Leite

Contra a arte patrocinada pelos que corrompem a liberdade de opção. Contra a arte fabricada para destruir o senso crítico, a emoção e a sensibilidade que nasce da múltipla escolha.

A Arte que liberta não pode vir da mão que escraviza.

A favor do batuque da cozinha que nasce na cozinha e sinhá não quer. Da poesia periférica que brota na porta do bar.

Do teatro que não vem do “ter ou não ter...”. Do cinema real que transmite ilusão.

Das Artes Plásticas, que, de concreto, quer substituir os barracos de madeiras.

Da Dança que desafoga no lago dos cisnes.

Da Música que não embala os adormecidos.

Da Literatura das ruas despertando nas calçadas.

A Periferia unida, no centro de todas as coisas.

Contra o racismo, a intolerância e as injustiças sociais das quais a arte vigente não fala.

Contra o artista surdo-mudo e a letra que não fala.

É preciso sugar da arte um novo tipo de artista: o artista-cidadão. Aquele que na sua arte não revoluciona o mundo, mas também não compactua com a mediocridade que imbeciliza um povo desprovido de oportunidades. Um artista a serviço da comunidade, do país. Que armado da verdade, por si só exercita a revolução. Contra a arte domingueira que defeca em nossa sala e nos hipnotiza no colo da poltrona.

Contra a barbárie que é a falta de bibliotecas, cinemas, museus, teatros e espaços para o acesso à produção cultural.

Contra reis e rainhas do castelo globalizado e quadril avantajado. Contra o capital que ignora o interior a favor do exterior. Miami pra eles?

“Me ame pra nós!".

Contra os carrascos e as vítimas do sistema.

Contra os covardes e eruditos de aquário.

Contra o artista serviçal escravo da vaidade.

Contra os vampiros das verbas públicas e arte privada.

A Arte que liberta não pode vir da mão que escraviza Por uma Periferia que nos une pelo amor, pela dor e pela cor.

É TUDO NOSSO! 
Em geral, o discurso passa por esse crivo, o que fatalmente incomoda e dá visibilidade para o grupo que também idealiza:

- Vencer o preconceito, as desigualdades materiais/culturais e o anonimato;

- Produzir, apresentar e consumir uma literatura de próprio punho, assim como transformar leitores em escritores;

- Expandir suas idéias espiritual e materialmente (Projeto Poesia no ar);

- Negar a vaidade e o que há de esnobe na figura do artista de elite;

- Tornar a periferia centro sem que ela deixe de ser periferia;

Antropofagia marginal periférica

- Fomentar a insubordinação transformada em autonomia (fim da caridade), como dizem "Nóis é ponte e atravessa qualquer rio"; ecoando das favelas

- Organizar seus rituais de pertencimento e acolhimento (Mestre de cerimônia anuncia a inscrição que está na entrada do bar "O silêncio é uma prece");

- Efetivar a democratização da escrita e da luta pela cidadania através da literatura.

Não podemos perder de vista que existe uma forte relação entre o movimento Hip Hop e a Cooperifa. Ainda que os poetas prezem a palavra em detrimento da música, como afirmam: "O silêncio é uma prece!", vários poemas recitados neste espaço de cultura e lazer alternativo criado pelos moradores da periferia, possuem uma musicalidade que os aproximam das batidas de rap ou do ritmo do samba, cantados nas favelas paulistanas.

Esses elementos de conexão entre a palavra e a música caracterizam a criação poética desses escritores às margens. A maioria deles começou escrevendo enredo para escolas de samba como sublinhou Paulo Lins em 2008 na $22^{\mathrm{a}}$ Bienal do Livro de São Paulo.

Vê-se uma união entre a linguagem culta e a linguagem popular urbana, ocorrendo assim uma espécie de hibridismo linguístico. Essa mistura de discursos pode ser compreendida como um reflexo da contradição de se estar à margem, no meio, no interstício ${ }^{7}$, no sem lugar que é a periferia. A mescla aparece na escrita representando uma re-apropriação da escrita no modo como ela foi formalizada, mas também como uma releitura propiciada pela linguagem oral periférica em oposição ao centro excludente.

7 BHABHA, Homi K. O local da cultura. (Tradução de Myriam Ávila, Eliana Lourenço de Lima Reis, Gláucia Renata Gonçalves). Belo Horizonte: Ed. UFMG, 1998. 
Por isso, a utilização da gíria apresenta-se como uma linguagem agressiva, cheia de códigos próprios do lugar periferia. Fortemente marcada por uma sonoridade de impacto, como se soasse no ouvido do leitor/ouvinte como uma rajada de palavras, essa literatura passa a ser a revelação de um campo semântico à margem repleto de brutalidades como resposta às injustiças, desigualdades e todas as formas de Raffaela discriminação. Entretanto, expressa uma das marcas da fala brasileira, Fernandez

Fernanda Mara

Campos Leite revelando códigos linguísticos que resgatam mecanismos de defesa da cultura afro-brasileira, mobilizados devido à exclusão sociolinguística e à violência do colonizador e suas práticas predatórias que se perpetuaram ao longo dos tempos.

Ao lermos os poemas dos poetas da Cooperifa (Sergio Vaz, Allan da Rosa, Márcio Barbosa, Akins, entre outros) percebemos uma intenção de representação do cotidiano periférico. São poetas que explicitamente declaram o que retratam em seus poemas: exclusão social, cultural, o afastamento das pessoas que vivem na periferia aos bens sociais, a violência, o crime e principalmente o sujeito da periferia como praticante da poesia, da prática social, ou seja, o homem periférico como um sujeito afetivo e coletivo.

Para tanto, esses poetas se veem como sujeitos que vivem na periferia e, então, são os representantes líricos desse lugar - assim como foram os compositores de samba do início do século XX, os narradores e cantadores do Nordeste, os prosadores e rimadores populares. $\mathrm{O}$ poema, uma forma, em geral, associada à "Literatura maior" e como mecanismo hierárquico de distinção dentro das artes desde Aristóteles, feito por poucos capazes de expressarem as grandiosidades da vida humana, é escolhida pelos líricos periféricos. No entanto, sabemos que arte poética na vida moderna: dos centros urbanos, da cidade vão representar o que os sujeitos vivem, sofrem e veem, sendo arte agora uma forma de expressão, transgressão, e/ou prática revolucionária da vida social, a arte tendo um papel de representação (mimeses) do cotidiano de uma faceta cruel do processo modernizador: as pobrezas.

Como registra Sérgio Vaz, para os poetas da Cooperifa o poema, é a forma de revelar e expressar a vivência na periferia, não como uma imitação, ou voz daquele que fala de fora, mas sim daquele que fala de dentro e re-apresenta aqueles que estão nas mesmas condições de relação social e não podem ou não conseguem enunciar/anunciar o que estão vivendo. É a opressão saindo da boca do oprimido. 
Ao lermos o histórico demarcado no livro e alguns poemas reproduzidos pelo autor descobrimos que a literatura criada por estes poetas não é só informação ou um documento da vida periférica. Primeiro é a produção de literaturas enquanto ação de recriação da palavra mobilizada, enquanto prática literária realizada em conjunto e esteticamente moderna no sentido da arte como representação da qual só pode falar da condição humana. Arte escrita coletivamente e conscientemente com as mesmas características linguísticas, nas quais estão inseridos seus poetas a partir de uma estética não da pobreza que comumente aliena, mas que expressa o saber e labor crítico tendo uma literalidade comum que congrega as partes. Segundo é uma forma discursiva que declara, relata e encara as outras formas discursivas alienantes, massivas e industriais, sendo esses muitas vezes os únicos materiais artísticos que chegam nas periferias, mas que são reciclados como forma de protesto criativo.

A antropofagia periférica inventada na Cooperifa está pronta para criticar e desconstruir imagens, relatos falsos da periferia, que é socialmente simbolizada como o despejo da sociedade ${ }^{8}$. São atos que permeiam toda a literatura do século XX e que retornam depois das atrocidades humanas exercidas nas guerras mundiais, reverberando ainda no cotidiano da vida urbana do século XXI.

Como Vaz nos mostra no capítulo 3, intitulado "Literatura, pão e poesia", através da função poética da linguagem os poetas da Cooperifa constroem a materialidade histórica e dialética da periferia, que critica o conflito dos espaços urbanos socialmente excluídos e oprimidos e, por conseguinte, são afastados dos centros artísticos e econômicos devido à intensa ligação entre arte e capital. A arte industrial, aquela que também é ligada ao mundo econômico produzida em massa serve como superação superficial do conflito social nas periferias. Cita por exemplo as telenovelas, que possuem como público maior o morador da periferia, pois a televisão é um objeto que existe na maioria das casas brasileiras, independentemente de classe sociail. Entretanto, através de seus poemas eles cantam durante as quartas-feiras (faz referência aos jogos de futebol consumido nas TVs nesse dia) “o que a novela não diz”, fazendo de seus poemas verdadeiros dispositivos de representações e luta contra a cultura de massa. Vaz reforça que essas vozes se auto-representam

8 Faço referência a imagem cunhada pela escritora Carolina Maria de Jesus em seu livro clássico sobre a favela paulistana, Quarto de despejo: diário de uma favelada, publicado em 1960. 
Raffaela

Fernandez

Fernanda Mara

Campos Leite

e se inserem por meio de suas palavras no universo da poesia, trazendo a público a poesia que há na vida das comunidades, criando assim “o lirismo do beco". Esses poetas colocam em evidência os sujeitos marginais periféricos, que são ouvidos pelos próprios periféricos e anunciam a arte da qual todo o ser humano pode ter, ouvir, ler independentemente de classe social, raça ou opção sexual.

Os poemas se inserem nos aspectos modernos da poesia, isto é, os versos são normalmente livres tendo alguns uma extensão prosaica, como igualmente as estrofes que se explicam por um aspecto imanente. As rimas encontradas em muito dos poemas são associadas a dois tipos de cantoria, podemos dizer três, só que uma também sofreu influência das outras duas. São elas, as rimas presentes no canto africano; as do canto do repente da região do nordeste brasileiro e do rap.

Como sabemos, muitos dos moradores da periferia de São Paulo vieram do Nordeste no êxodo rural. O repente é desafio feito por trovadores, ou líricos como era na Idade Média que rimavam sobre um assunto e no Nordeste é feito por "cantadores", desembocando na literatura de cordel. o terceiro canto é o do rap, que significa ritmo e poesia na tradução direta do inglês. 0 rap é um dos elementos da cultura Hip-Hop inventado por homens socialmente marginalizados, que buscavam e buscam expressar seus valores, ideais e o cotidiano dos lugares onde vivem, por meio desse canto ritmado e poético que funciona como "comunicadores sociais":

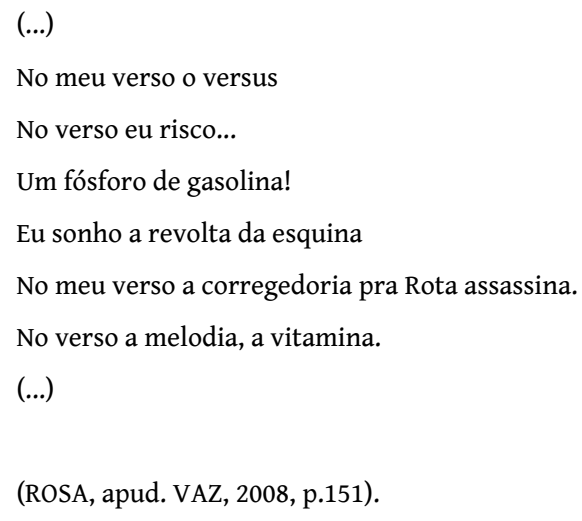

9 Cf. SANTOS, Milton. Metamorfoses do espaço habitado: fundamentos teórico e metodológico da geografia. São Paulo: Hucite, 1988. 
No entanto, o rap tem uma influência do segundo canto, o africano, na batida, no ritmo e é também feita por uma maioria negra. 0 rap aqui no Brasil terá uma influência do repente, pois tem a ideia do ritmo rápido, da rima simples e da embolada praticada por migrantes ou seus descendentes nas festas das favelas paulistanas e em todo país. Nos poemas marginais-periféricos, a distribuição das rimas liga-se a esses três cantos, além da referência temática abordando sempre aspectos de uma ideia de identidade histórico-social e artística dos espaços de confraternização das margens.

Quanto aos aspectos imanentes dos poemas, podemos dizer que são evocados pela descrição da movimentação no espaço urbano periférico, referindo-se a um lugar restrito ao eu - lírico marginalizado. Os poemas tendem a mostrar uma visão dos atos e fatos das relações so-

Antropofagia marginal periférica ecoando das favelas ciais estabelecidas no local da marginalidade, principalmente os conflitos sociais e violências, visando um lirismo atuante no seu canto e na expressão de seus sentimentos, aprimorando o diálogo entre ouvintes e leitores, num flagrante anseio de desenvolver uma consciência político-literária entre os seus: é a voz do oprimido falada para seu igual com o objetivo de chamar para luta e sensibilização do lugar social através da palavra.

O último aspecto é algo sempre evidenciado, o fato da linguagem cotidiana, dos termos, das palavras, das gírias e dos códigos marcarem os poemas. A escrita referencia a realidade e sua forma de se comunicar nela. De modo que, os poemas possuem essa característica não por uma falta de conhecimento da língua culta, mas por uma identificação e uma busca de comunicação poética direta com as relações de um mundo próprio, do espaço poético que emerge dos becos e nas vielas:

FAVELA

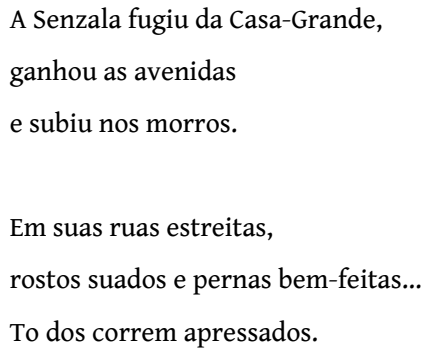


Em cada casebre,

velhos rugosos e rostos imberbes

procuram, dia a dia,

ganhar o pão e o chão.

Nem sol, nem chuva

Raffaela

nem a lei da gravidade

abalam a firme estrutura

desta pseudocidade.

Fernanda Mara

Campos Leite

Mil novos Quilombos

se erguem aos tombos

484

na chamada civilização,

com rios de asfalto

e palmeiras de plástico,

sem

cor nem umidade:

São Palmares de verdade !

A Senzala mudou de nome;

batizaram-na Favela

que por nós vela,

do alto do morro.

Tornou-se Casa-Grande

e todos nós, restantes

nos transformamos na Senzala

da Cidade Grande.

Marcelo Lopes ${ }^{10}$

A norma eurocêntrica ou norte-americana de estética moderna há muito já não corrobora para pensar as práticas artístico-culturais e os lugares enunciativos tomados como periféricos pelos discursos hege-

$101^{\circ}$ lugar no Concurso Prêmio Pérolas de Poesias, promovido pela Secretaria de Cultura/Pref ${ }^{\mathrm{a}} \mathrm{Mu}-$ nic. de Guarulhos, 2005, SP e $2^{\circ}$ lugar no $1^{\circ}$ Concurso de Poesia de São Bentinho, Prêmio Belarmino França, 2006, PB. 
mônicos da arte, da literatura, da cultura ou da ciência como produtora de conhecimento desde que o mundo é mundo. Como nos mostra Vaz, pensar este novo aparato cultural demanda um posicionamento diferenciado, metamorfoseado e multidisciplinar que possa abarcar esses sujeitos fora dos lugares enunciativos do poder hegemônico e cristalizadores da arte, da literatura e da cultura.

Em 2013, um livro lançado pelo professor João Camillo Penna, Escritos da sobrevivência, pela editora 7 Letras, fez-nos refletir ainda mais sobre este processo de inserção e/ou inclusão pelo qual se firmou o movimento de Literatura Periférica no âmbito cultural: a inserção e/ou inclusão pode ser compreendida como um conjunto de empreendimentos de reequilíbrio para recuperar a distância em relação a uma completa integração (um quadro de vida decente, uma escolaridade "normal", Antropofagia marginal periférica ecoando das favelas um emprego estável etc.) (PENNA, 2013, p.281). Desse modo, podemos perceber que para além dos traços linguísticos particulares, há também outro traço muito importante no que se refere à produção, recepção e circulação dessa literatura. Como exemplo, temos o poeta Allan da Rosa, supracitado, que criou a marca Edições Toró ${ }^{11}$, em 2005, no intuito de publicar os livros dos poetas do Sarau Cooperifa. Segundo uma entrevista dada ao canal CyberQuilombo ${ }^{12}$, em 2015, para Da Rosa, a editora surge sob a necessidade de se fortalecer como movimento de Literatura.

No entanto, apesar de satisfatório, ainda se faz necessária a parceria com grandes editoras, o que viabiliza o contorno dos desafios os quais por hora não se pode assumir. A mediação ${ }^{13}$ editorial parece assustadora para uns, enquanto para outros, e Allan é um deles, uma possibilidade de desgeografizar a atuação, ampliando os horizontes de intervenção. Um pensamento novo mediante um novo tempo. Diz-nos, assim: “(...) esse é o papel de uma grande editora para a gente: a capacitação, a potencialização da circulação e da distribuição" ${ }^{14}$, também, "cada geração tem suas urgências" 15 na caçada pelo autoentendimento sincrônico do movimento.

$\mathrm{O}$ acesso a uma grande editora tem como vantagem um diálogo facilitado com os órgãos públicos, como as Secretarias de Educação e Cultura, avançando, assim, quanto ao amparo que a literatura margi-

\footnotetext{
11 Disponível em: http://www.edicoestoro.net/ (acesso no dia 04/07/2017, às 13h00).

12 Disponível em: http://labexperimental.org/cyberquilombo/ (acesso dia 04/07/2017, às 13h05).

13 “A mediação, por sua vez, pode ser entendida (...)" (p.282).

14 PEÇANHA, Érica, et al. Polifonias Marginais.-1.ed.- Rio de Janeiro: Aeroplano, 2015. (p.92).

15 Ibidem (p.93).
} 


\section{Raffaela \\ Fernandez \\ Fernanda Mara \\ Campos Leite}

nal pode oferecer no que se refere ao aprendizado de história e cultura afro-brasileira. Eis aqui um ponto de muita importância: o caráter expansivo dessa literatura, que se faz vivo e dá vida às disputas de narrativa social, uma vez que configura um grande passo a caminho da soberania dos sujeitos marginalizados, dando forma à força política.

A experiência de exclusão que une as literaturas periféricas marginais confere a esta uma livre transitoriedade entre vida e arte; talvez, daí a potencialidade de se infiltrar mesmo nos espaços mais elitizados, como os de promoção do conhecimento, ao mesmo tempo em que constitui e constrói o lugar "periferia". Constitui, porque é parte integrante deste organismo; e, constrói, pois confere o acesso à Literatura, à Leitura, ao conhecimento, muito para além do conhecimento de mundo, um conhecimento de si: "escrever para entender melhor a si mesmo"16.

Essa apropriação histórica salienta-nos o quão singular é a questão da identidade quando falamos de um texto da periferia (origem), pensado e celebrado por periféricos. O texto situa, alimenta e encoraja quem se deixa afetar por ele, seja pela palavra lida, seja pela palavra ouvida. Não mais passa pela objetificação, mas pela sujeitificação daqueles para quem se produz o texto, e o contato com o interlocutor é um verdadeiro exercício de posse recíproca, um pertence ao outro: "o leitor lê o texto, mas o texto também lê o leitor".

No último livro publicado pelo escritor Allan, Reza de mãe, isso se mostra muito evidente para nós. Logo nas primeiras páginas, nos deparamos com "Pode ligar o chuveiro?"17, conto que retrata o cotidiano de uma família a sofrer com as exigências e tarifas abusivas das empresas de energia e acaba por ter de inventar maneiras de burlar o sistema. Personagem a personagem, cada uma revela suas impressões da vida à mercê da metrópole, não somente como queixa constitutiva dos sujeitos, mas também como parte inerente a sua própria formação. Segue um trecho do conto:

\footnotetext{
Tem alguém tomando banho aê!?

Limpar o doce, tirar essa pegalança do couro.

É Valdeci entrar no metrô e todo povo empina o nariz, fareja de onde vem esse aroma pesado, vapor enjoativo que impregna o vagão. Nhaca de açúcar.
}

16 Ibidem (p.79).

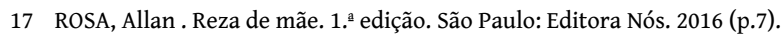




\section{(...)}

E ele em casa é o burguês, trabalha em horário de galeria e não madruga pra sair. Atravessa o bairro do Almeida, embarca no metrô Jabaquara e meio-dia levanta a porta. Minhoqueiro vai pelos debaixos do metrô, vocação toupeira, depois formiga na lida com o açúcar. Doce a Vida. Mas bem antes de entrar em vagão, mesmo antes de pisar no tapetinho da cama, já se levanta com as dobras do braço se grudando.

Antropofagia marginal periférica No pescoço parece ter cola.

Põe mais doce de leite aí! Enche pra mim, quero escorrendo, deixa de ser miserável!

Ontem uma guriazinha tirando em francês, as colegas mangando do servente.

(...)

Clientela poliglota de 12 anos de idade. Churro, cherrí? Vou botar mais sim, mademoizéli.

(...)

Na lida, o que não falta é gente e situação. Pra Valdeci o dia inteiro de pé, joia é deixar água cair pelando no tornozelo, escaldar na bacia com capim-limão e flor de laranjeira.

Esfrega, quase se lixa, mas dá sábado, dá domingo, e esse açúcar não larga nas dobrinhas do braço. Humilhação grudada na pele, raiva peguenta, até atrás do joelho fica melando, entra por baixo do avental e da calça. Como chega ali esse açúcar?

(...) (ROSA,2016, p.7).

No trecho, podemos observar o relato de Valdeci, um vendedor de churros, que tem seu ponto de venda na frente de um colégio particular, onde os pré e adolescentes senhores de si e de sua própria vontade, zombam do trabalhador em outro idioma, dia após dia. Ali, carregado da indigestão, o homem tem de engolir a humilhação que lhe fazem e sorrir, ainda pensando nos olhares de demérito que terá de enfrentar no metrô na volta pra casa; para, enfim, banhar-se na intenção de despir-se desta quase segunda pele que o esmaga na correria da luta pelas mínimas condições de vida dentro dos grandes centros urbanos.

A escrita sobre a realidade marginal é um abraço de fraternidade para quem se identifica com Valdeci; como já dissemos, um pertencimento recíproco, um pertence ao outro: “o leitor lê o texto, mas o texto 
também lê o leitor". E nesse jogo fronteiriço que percorre vida e literatura, as identidades se criam, recriam, afirmam e reafirmam-se o tempo todo. Linha a linha, a representatividade calcada sobre a descrição atenta e sensível do cotidiano promove a periferia como protagonista da cena corriqueira, colocando-a no centro.

Outra inclinação importante no campo da Literatura Marginal Raffaela periférica paulistana são as narrativas das experiências de negritude, Fernandez ademais das experiências periféricas, que se inscrevem na produção atual, dando seguimento à ideia de promoção do autoconhecimento, ou

Fernanda Mara

Campos Leite mesmo de luta por reconhecimento político e histórico. Mais do que nunca se amplia a busca pela múltipla representatividade nas periferias, representá-la para além das caixinhas. Um apontamento, outro, para a fuga das ciladas que impõe a indústria cultural ao pré-estabelecer o lugar da periferia no mercado literário.

\section{REFERÊNCIAS}

BHABHA, Homi K. O local da cultura. (Tradução de Myriam Ávila, Eliana Lourenço de Lima Reis, Gláucia Renata Gonçalves). Belo Horizonte: Ed. UFMG, 1998.

CLASTRES, Pierre. Arqueologia da violência. 2. ed. São Paulo: Cosac Naify, 1980. 328 p.

FREUD, Sigmund. Esboço de psicanálise. 1. a ed. Imago Editora, 1998.

HONNETH, Axel. Luta por reconhecimento: A gramática moral dos conflitos sociais. Trad. de Luiz Repa. São Paulo: Ed. 34, 2003.

PEÇANHA, Érica, et al. Polifonias Marginais. 1.ed. Rio de Janeiro: Aeroplano, 2015.

PENNA, João Camillo. Escritos da sobrevivência. Rio de Janeiro: 7Letras, 2013.

ROSA, Allan. Reza de mãe. 1. ㄹ ed. São Paulo: Editora Nós, 2016. 
SANTOS, Milton. Metamorfoses do espaço habitado: fundamentos teórico e metodológico da geografia. São Paulo: Hucite, 1988.

VAZ, Sergio. Cooperifa: antropofagia periférica. Rio de Janeiro: Aeroplano, 2008.

\author{
Antropofagia \\ marginal \\ periférica \\ ecoando das \\ favelas
}


